EDITORIAL

\title{
LA INVESTIGACIÓN CIENTÍFICA Y TECNOLÓGICA EN CHILE
}

La ingeniería es un conjunto de disciplinas aplicadas que dependen de la ciencia, pero que en si mismas no son ciencias. Es una función del ingeniero el desarrollar soluciones técnicas ante problemas prácticos. Al hacerlo emplea la tecnología, que con frecuencia surge de la ciencia, pero que en si misma no es ciencia. La tecnología incluye métodos y materiales técnicos para alcanzar objetivos prácticos. Es correcto y adecuado esperar y exigir soluciones a los problemas prácticos a los ingenieros. Nuestro país tiene una producción casi nula de patentes industriales, por lo que resulta interesante analizar las causas de este hecho y del escaso desarrollo tecnológico que ostentamos.

En estudios realizados respecto de capital humano en Chile se ha coincidido en la caracterización de algunos de los problemas más relevantes. Estos son:

- escasa formación de doctores,

- poca investigación aplicada,

- bajos gastos en innovación y desarrollo,

- escaso aporte de las empresas en estas materias.

También se puede apreciar que la interesante producción científica-tecnológica, reflejada en escritura de artículos en revistas especializadas, no tiene la correspondiente contraparte en la generación de patentes industriales.

Los investigadores de la Universidad Adolfo Ibáñez de Chile, José Joaquín Brunner y Gregory Elacqua, sostienen que Chile no sólo invierte un escaso porcentaje de su producto interno bruto, en desarrollo tecnológico, sino que también lo distribuye en diferente forma que en los países industrializados. El aporte de las empresas es de alrededor de un 15\%, mientras que en los países industrializados es de $69 \%$.

Respecto al trabajo académico, se detecta que sólo un $15 \%$ de los académicos del país se dedican a actividades de investigación y desarrollo. Esta cifra es claramente insuficiente; en nuestro país apenas hay 12 personas dedicadas al trabajo científico-tecnológico, por cada 10 mil integrantes de la fuerza laboral mientras que en los países industrializados esta cifra oscila entre 50 y 100.

Como las universidades realizan la mayor parte de este trabajo, centran su atención en programas de ciencias básicas y no trabajan en áreas que tengan un espacio de aplicación práctica, por lo que los doctorados que se prefieren son los vinculados con las ciencias 
básicas. En los países industrializados se ha logrado comprender que es una función de la universidad desarrollar conocimientos que puedan ser aplicados al crecimiento y al desarrollo económico del país.

Uno de los problemas que representa la educación superior en Chile es la escasa formación de personal científico y tecnológico que posea el grado de doctor. Chile sólo forma cuatro doctores por cada millón de habitantes, frente a los ocho de México, once de Argentina y dieciocho de Brasil. La meta en Chile, según fuentes del Ministerio de Educación es formar, para el año 2010, de 500 a 600 doctores anualmente.

Mejorar en estos aspectos, según José Joaquín Brunner, requiere de una política de postgrado completamente distinta, es decir formar mucha gente que se dedique a la investigación aplicada y desarrollar doctorados, en todas aquellas áreas, donde necesitamos mejorar la calidad de la docencia e investigación a través de académicos con mejor formación en ciencias aplicadas. 